\title{
Inhibition of Transforming Growth Factor $\beta$ Worsens Elastin Degradation in a Murine Model of Kawasaki Disease
}

\author{
Cristina M. Alvira, ${ }^{*}$ Christophe Guignabert, ${ }^{* \dagger}$ \\ Yu-Mee Kim, ${ }^{*}$ Chihhsin Chen, ${ }^{*}$ Lingli Wang, ${ }^{*}$ \\ Trang T. Duong, ${ }^{\ddagger}$ Rae S.M. Yeung, ${ }^{\ddagger}$ Dean Y. Li, ${ }^{\S}$ \\ and Marlene Rabinovitch* \\ From the Department of Pediatrics," Stanford University School of \\ Medicine, Stanford, California; INSERM U999, Centre Chirurgical \\ Marie Lannelongue, Le Plessis-Robinson, Orsay, France; the Cell \\ Biology Program, ${ }^{\ddagger}$ Hospital for Sick Children, University of Toronto, \\ Toronto, Ontario, Canada; and the Program in Molecular \\ Medicine, ${ }^{\S}$ University of Utah, Salt Lake City, Utah
}

Kawasaki disease (KD) is an acute inflammatory illness marked by coronary arteritis. However, the factors increasing susceptibility to coronary artery lesions are unknown. Because transforming growth factor (TGF) $\beta$ increases elastin synthesis and suppresses proteolysis, we hypothesized that, in contrast to the benefit observed in aneurysms forming in those with Marfan syndrome, inhibition of TGF- $\beta$ would worsen inflammatory-induced coronary artery lesions. By using a murine model of KD in which injection of Lactobacillus casei wall extract (LCWE) induces coronary arteritis, we show that LCWE increased TGF- $\beta$ signaling in the coronary smooth muscle cells beginning at 2 days and continuing through 14 days, the point of peak coronary inflammation. By 42 days, LCWE caused fragmentation of the internal and external elastic lamina. Blocking TGF- $\beta$ by administration of a neutralizing antibody accentuated the LCWE-mediated fragmentation of elastin and induced an overall loss of medial elastin without increasing the inflammatory response. We attributed these increased pathological characteristics to a reduction in the proteolytic inhibitor, plasminogen activator inhibitor-1, and an associated threefold increase in matrix metalloproteinase 9 activity compared with LCWE alone. Therefore, our data demonstrate that in the coronary arteritis associated with $\mathrm{KD}$, TGF- $\beta$ suppresses elastin degradation by inhibiting plasmin-mediated matrix metalloproteinase 9 activation. Thus, strategies to block TGF- $\beta$, used in those with Marfan syndrome, are unlikely to be beneficial and could be detrimental. (Am J Pathol 2011, 178:1210-1220; DOI: 10.1016/j.ajpath.2010.11.054)

Kawasaki disease (KD) is an acute inflammatory disease marked by vasculitis of small and medium arteries, most commonly affecting the coronary arteries. Kawasaki disease remains a leading cause of acquired heart disease in children, ${ }^{1,2}$ with approximately $25 \%$ of untreated and $5 \%$ of treated patients developing coronary artery lesions (CALs), including aneurysms. Although episodic outbreaks suggest an infectious cause, a specific pathogen has not been identified. ${ }^{3}$ Genetic factors appear to influence disease susceptibility and severity, with an increased incidence in patients of Japanese heritage and in children whose relatives have a history of ${ }^{4}$; in addition, there is a greater risk of giant coronary artery aneurysms in patients with recurrent KD. ${ }^{5}$ Therefore, it is likely that an inflammatory stimulus in combination with specific host factors is required for CAL development.

In Marfan syndrome (MS), aortic aneurysms form as a result of a genetic defect in fibrillin-1, a microfibrillar protein important in elastin assembly. Fibrillin-1 binds the cytokine transforming growth factor (TGF) $\beta$ in an inactive form. Deficiency of fibrillin-1 leads to inappropriate activation of TGF- $\beta$ and appears to be critical to the development of aneurysms observed in MS. However, the mechanisms responsible for this pathological effect remain unknown. In the

Supported by grants from the American Heart Association Fellow to Faculty Award (C.M.A.); the Canadian Institutes for Health Research FRN 53245 (R.S.M.Y.); Arthritis Society of Canada Investigator Award (R.S.M.Y.); the H.A. and Edna Benning Foundation (D.Y.L.); the Burroughs Wellcome Foundation (D.Y.L.); the Juvenile Diabetes Research Foundation (D.Y.L.); the American Heart Association (D.Y.L.); the National Heart, Lung, and Blood Institute (D.Y.L.); the National Institutes of Health (grant RO1 HL074186 to M.R.); and the Dunlevie Chair in Pediatric Cardiology (M.R.).

Accepted for publication November 9, 2010.

Supplemental material for this article can be found at http://ajp. amjpathol.org or at doi:10.1016/j.ajpath.2010.11.054.

Address reprint requests to Marlene Rabinovitch, M.D., Stanford University School of Medicine, 269 Campus Dr, CCSR Room 2245B, Stanford, CA 94305-5162. E-mail: marlener@stanford.edu. 
murine model of MS, TGF- $\beta$ blockade with either a neutralizing antibody (nAb) or the angiotensin-II receptor antagonist, losartan, effectively prevented aortic dilation and induced regression of established disease. ${ }^{6}$ Furthermore, in a clinical study ${ }^{7}$ in pediatric patients with MS, losartan therapy was effective in decreasing the rate of aortic root dilation. As a result of these studies, there has been speculation that increased TGF- $\beta$ activation is related to non-MS aneurysm formation, leading to interest in extrapolating the use of TGF- $\beta$ blockade to treat conditions such as abdominal aortic aneurysm and KD. ${ }^{8}$

However, this therapeutic strategy may be detrimental in aneurysms that form in response to inflammatory stimuli, such as KD, considering the anti-inflammatory properties of TGF- $\beta$ (ie, inhibition of T-cell proliferation and inflammatory cytokine expression). ${ }^{9}{ }^{10}$ Moreover, TGF- $\beta$ induces genes important in elastin fiber assembly (eg, tropoelastin) ${ }^{11-13}$ and limits elastin degradation by increasing tissue inhibitors of matrix metalloproteinases (TIMPs) and plasminogen activator inhibitor (PAl) 1. ${ }^{14,15}$ In fact, in a xenograft model of aortic aneurysm marked by inflammation and proteolysis, transfection of TGF- $\beta$ limited aortic dilation by preserving medial elastin and decreasing matrix metalloproteinase (MMP) 2 and MMP-9 activity. ${ }^{16}$ Therefore, better defining the role of TGF- $\beta$ in diseases marked by inflammation and aneurysm formation will have major therapeutic implications. The role of TGF- $\beta$ in the pathogenesis of aneurysms occurring in young patients is particularly unclear, given that our knowledge is almost exclusively derived from animal models of aneurysm formed by caustic chemical infusions $^{17,18}$ or that develop in association with atherosclerosis. ${ }^{19}$

To address these issues, we used a murine model of KD, in which the injection of Lactobacillus casei wall extract (LCWE) induces coronary arteritis. ${ }^{20-22}$ Because KD is almost exclusively a pediatric illness, we treated mice in the first few weeks of life with LCWE and determined the effect of blocking TGF- $\beta$ during this process. We hypothesized that, in contrast to the effect in MS, the induction of TGF- $\beta$ in response to LCWE would be protective, stimulating new tropoelastin synthesis and decreasing proteolytic activity. Consistent with this hypothesis, we show that TGF- $\beta$ blockade worsens elastin degradation and decreases levels of medial elastin, without affecting the expression of tropoelastin or increasing the degree of coronary arteritis. We attribute this protective effect to the ability of TGF- $\beta$ to preserve the levels of the plasmin inhibitor, PAI-1, and thereby to suppress activation of the elastolytic protease, MMP-9. Interestingly, LCWE induces similar pathological characteristics in adult mice that are also aggravated by TGF- $\beta$ inhibition, suggesting that, in addition to $K D$, these results may be generalizable to forms of inflammatory aneurysms affecting older patients.

\section{Materials and Methods}

\section{Murine Model of KD}

Coronary arteritis was induced in neonatal (7-day) C57/ BL6/129S mice by injection of $20 \mathrm{mg} / \mathrm{kg}$ (rhamnose equivalent) of LCWE i.p. or an equal volume of vehicle (PBS), as used previously in an accepted animal model of KD. ${ }^{21,22}$ Mice were sacrificed at 2 and 14 days, the hearts were perfused with PBS, and then either prepared for histological analysis or snap frozen for RNA and protein extraction. At 42 days, mice were anesthetized and sacrificed by exsanguination and the coronary circulation was perfused under physiological perfusion pressure by injecting barium gelatin through the left ventricle after ligating the ascending aorta. The heart and aortic root were then fixed en bloc in formalin for assessment of coronary artery morphological features and elastin integrity. All surgical and animal care procedures and experimental protocols were reviewed and approved by the Institutional Animal Care and Use Committee of Stanford University, Stanford, California.

\section{Elastin Staining and Determination of Elastin Content}

The integrity of the coronary elastin was visualized by light microscopy after Hart's elastin staining. ${ }^{23}$ Cross sections of the large coronary arteries under $\times 40$ magnification were evaluated in a blinded fashion, and the number of visible breaks was measured per 1000- $\mu \mathrm{m}$ length of vessel wall. The amount of medial elastin was quantified by determining the total amount of stained elastin versus total medial area using a commercially available system (Bioquant True Color Windows Image Analysis system; R \& M Biometrics, Nashville, TN) in cross sections of the large and medium coronary branches in a blinded fashion.

\section{Masson Trichrome Staining}

To assess collagen and the nonelastin matrix, formalinfixed sections of the large coronary arteries were soaked in Bouin's solution overnight and then stained using a kit (Accustain Trichrome Kit; Sigma, St Louis, MO). Representative images of the large coronary arteries were obtained under $\times 40$ magnification. The total percentage matrix area versus the total cross-sectional area of the vessel was determined in a blinded fashion using Metamorph Image Analysis software (Leeds Precision Instruments, Minneapolis, MN).

\section{Immunostaining for Phosphorylated Smad2/3}

Immunohistochemical staining was performed on FFPE sections after antigen retrieval by heating sections in citrate buffer at $95^{\circ} \mathrm{C}$ for 10 minutes. Sections were then incubated with anti-phosphorylated mothers against decapentaplegic homolog 2/3 (pSmad2/3) antibody (1:200; Cell Signaling, Danvers, MA) overnight at $4^{\circ} \mathrm{C}$, followed by detection with a commercially available system (Vectastain ABC system; Vector Laboratories, Burlingame, CA), and counterstained with hematoxylin (Sigma Aldrich, Mountain View, CA). Images were quantified by determining the percentage of brown- versus total-stained nuclei in a blinded fashion with computer software (MetaMorph Imaging). 


\section{Inhibition of TGF- $\beta$ Signaling}

Additional neonatal mice were used in experiments to determine the effect of blocking TGF- $\beta$ activity on LCWEmediated coronary pathological features. Mice were injected with either $10 \mathrm{mg} / \mathrm{kg}$ i.p. pan-sensitive TGF- $\beta$ nAb or rabbit IgG (R\&D Systems, Minneapolis), daily (three doses), beginning 24 hours before LCWE treatment, and then weekly thereafter for 2 weeks, a strategy previously described as effective in blocking the TGF- $\beta$ activity observed in the murine model of MS. ${ }^{6}$ Additional groups of animals were treated with either the TGF- $\beta$ nAb or rabbit IgG on an identical schedule but without LCWE. The mice were sacrificed at 2, 14, and 42 days after treatment for the analyses previously described. A similar experimental design was used to study the impact of LCWE with or without TGF- $\beta \mathrm{nAb}$ in adult mice (aged 5 weeks).

\section{Immunoblotting}

Protein was extracted from frozen heart tissue using a kit (NE-PER kit; Pierce, Rockford, IL) containing protease inhibitors, and $60 \mu \mathrm{g}$ was resolved on $4 \%$ to $12 \%$ gels (NuPage Bis-Tris gels; Invitrogen, Carlsbad, CA) and electrotransferred to nitrocellulose membranes. ${ }^{24} \mathrm{Mem}$ branes were incubated overnight at $4^{\circ} \mathrm{C}$ with primary antibodies for PAI-1 (1:1000; BD Biosciences, San Jose, $\mathrm{CA}$ ), incubated with anti-mouse horseradish peroxidase (1:5000; Santa Cruz Biotechnology, Santa Cruz, CA) and Enhanced Chemiluminescence (ECL) substrate (GE Health Care, Piscataway, $\mathrm{NJ}$ ), and the signal was then developed by exposure to Hyperfilm. Membranes were stripped and reprobed for $\alpha$-tubulin (1:10,000; Sigma) as a housekeeping gene.

\section{Quantitative PCR}

Total RNA was extracted from the upper heart (including the aortic root), and $2 \mu \mathrm{g}$ of RNA was reverse transcribed to cDNA using (Superscript III; Invitrogen) per the manufacturer's protocol. Quantitative PCR was performed using primers (TaqMan; Applied Biosystems, Foster City, CA) for tumor necrosis factor (TNF) $\alpha$ (Mm00443258_m1), MMP-9 (Mm00442991_m1), collagen1- $\alpha 1$ (Mm011302043_g1), collagen1- $\alpha 2$ (Mm00483937_m1), collagen6- $\alpha 1$ (Mm00487160_m1), fibrillin-1 (Mm00514908_m1), laminin- $\alpha 5$ (Mm01222029_m1), and Iaminin- $\beta 2$ (Mm00493080_m1), using the relative standard curve method of analysis with expression of the target genes normalized to $18 \mathrm{~S}$ and a real-time PCR instrument (model 7900HT; Applied Biosystems).

\section{Gelatin Zymography}

Total heart tissue obtained from the four groups (IgG, TGF- $\beta$ nAb, LCWE plus IgG, and LCWE plus TGF- $\beta$ nAb) was homogenized in ice-cold PBS. A total of $30 \mu \mathrm{g}$ of protein was then resolved on $10 \%$ SDS gels containing $0.1 \%$ gelatin (Invitrogen). ${ }^{25}$ The gels were stained with Coomassie blue, and the bands of gelatinolytic activity were quantified using imaging software (Quantity One; Bio-Rad, Hercules, CA).

\section{Statistical Analysis}

All data are presented as the mean \pm SEM. The number of animals used in each determination is given in the legends for the figures. Statistical differences between the two groups were determined by the Student's $t$-test. Statistical differences involving comparison of more than two groups were determined by one-way analysis of variance, followed by Bonferroni's multiple comparison post hoc analysis. $P \leq$ 0.05 was considered statistically significant.

\section{Results}

\section{LCWE Increases TGF- $\beta$ Signaling in the Coronary Wall and Induces Coronary Arteritis}

To study to role of TGF- $\beta$ in inflammatory aneurysm formation, we injected neonatal mice with LCWE, an agent that produces coronary arteritis and elastin degradation similar to that observed in KD. 21,22,26,27 We first examined the activation of TGF- $\beta$ in the coronary arteries by performing immunohistochemistry to detect pSmad2/3, the intracellular molecule that translocates into the nucleus in response to TGF- $\beta$ signaling. A moderate amount of nuclear pSmad2/3 was observed in the neonatal coronary artery endothelium, adventitia, and cardiac myocytes in vehicle-treated controls 2 days after the start of the experiment (Figure 1A). The LCWE induced marked nuclear pSmad2/3 staining in the coronary smooth muscle cells and augmented basal signaling in the endothelium, adventitial cells, and cardiac myocytes $(P<0.0001)$. By 14 days, the nuclear pSmad2/3 had decreased in the LCWE-treated mice, with a similar degree of pSmad2/3 expression observed in the coronary endothelium and smooth muscle cells in LCWEtreated and control animals (Figure 1B). However, persistent prominent immunoreactivity remained in the perivascular cells of the LCWE mice. At this same point, examination of $\mathrm{H} \& E$-stained sections revealed that LCWE treatment caused a modest degree of perivascular inflammation in the coronary arteries (Figure $1 \mathrm{C})$.

\section{LCWE Induces Fragmentation of the Coronary Artery Elastin}

Next, we evaluated the integrity of the coronary elastin by Hart's staining 42 days after LCWE, the point when previous studies $^{21,22}$ have demonstrated that LCWE causes elastin breakdown, an early feature of CAL. Compared with vehicle controls, the coronary arteries of the LCWEtreated mice demonstrated thinning and flattening of the internal elastic lamina and fraying of the external elastic lamina, with multiple areas of fragmentation (Figure 2A). When we quantified the number of visible breaks in the 


\section{A}

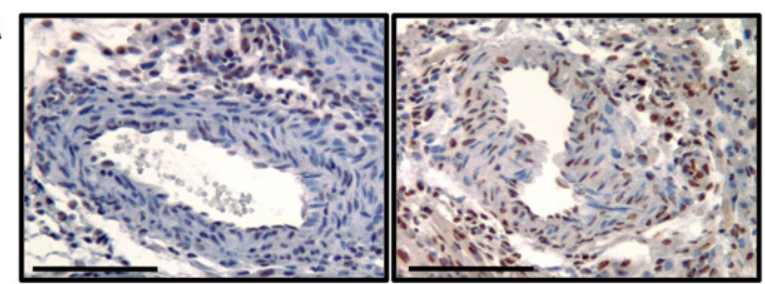

Control

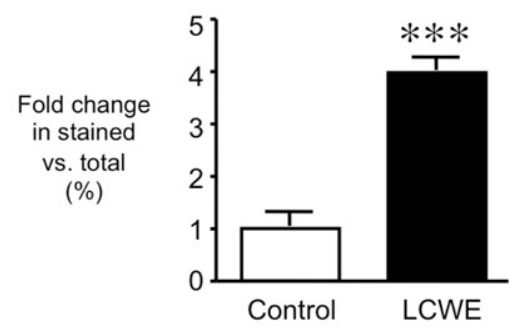

B
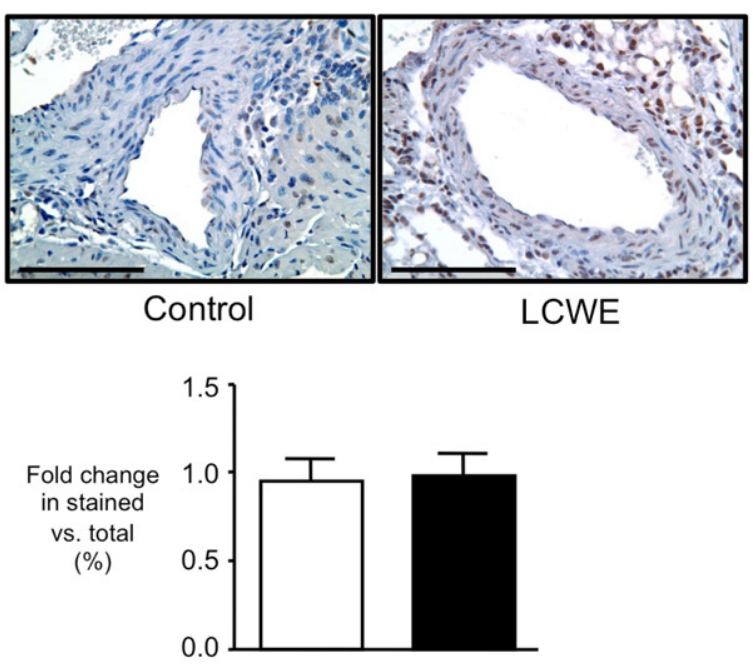

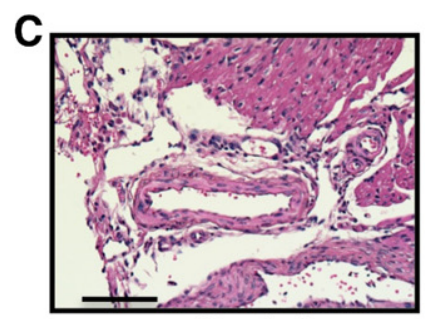

Control

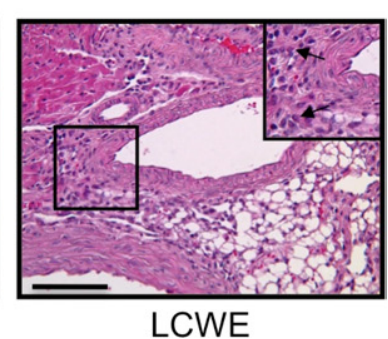

LCWE
Figure 1. The LCWE induces TGF- $\beta$ signaling in the coronary wall and coronary arteritis in neonatal mice. A: Representative sections of the coronary arteries after immunostaining to detect $\mathrm{pSmad} 2 / 3$ after either PBS or LCWE injection at 2 days (A) and 14 days $(\mathbf{B})$. Total area of brown-stained versus total nuclei quantified within the coronary wall and expressed as fold change over control. ${ }^{* * * * *} P<0.0001$ versus control. Bars represent mean \pm SEM ( $n=$ 4 to 11 sections counted per group). C: Representative H\&E sections of the coronary arteries 14 days after PBS or LCWE demonstrate perivascular inflammatory cell infiltration (arrows) in the LCWE-treated animals. Scale bars $=100 \mu \mathrm{m}$.

elastic lamina and the total amount of elastin within the coronary media, we found that while LCWE caused a significant disruption of the integrity of the external elastic lamina (Figure 2B), the total amount of medial elastin was not significantly lower than that found in control mice (Figure 2C).
TGF- $\beta$ Blockade Increases LCWE-Mediated Elastin Degradation Without Increasing Arteritis or Suppressing Tropoelastin Expression

To determine whether the LCWE-mediated induction of TGF- $\beta$ contributed to the pathological features observed (ie, inflammation and elastin fragmentation) or served a protective role, we blocked TGF- $\beta$ by administering a pan-sensitive TGF- $\beta$ nAb to the neonatal mice beginning 1 day before LCWE treatment and continuing through the induction of arteritis at 14 days. Additional groups of mice were treated with isotype control IgG in addition to LCWE or with either IgG or TGF- $\beta$ nAb in the absence of LCWE. Immunostaining for nuclear pSmad2/3 demonstrated that TGF- $\beta$ nAb administration reduced the LCWE-mediated induction of TGF- $\beta$ signaling in the coronary wall at 2 days $(P=0.013)$ (Figure 3$)$.

Transforming growth factor $\beta$ is an important regulator of inflammation; therefore, we examined whether blocking TGF- $\beta$ altered the extent of coronary arteritis induced by LCWE at 14 days. Evaluation of H\&E-stained sections of the coronary arteries taken from LCWE plus IgG and LCWE plus TGF- $\beta$ nAb-treated mice at 14 days demonstrated similar degrees of perivascular inflammation in both groups (Figure 4A). As an additional measure of the inflammatory response, we determined whether the expression of TNF- $\alpha$, a proinflammatory cytokine increased in the heart after LCWE and necessary for the induction of LCWE-mediated coronary arteritis, ${ }^{20}$ was modulated by neutralizing TGF- $\beta$. Increased TNF- $\alpha$ mRNA levels were

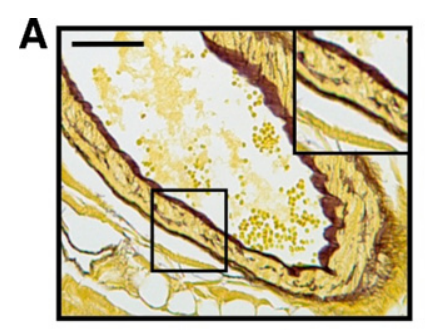

Control

B

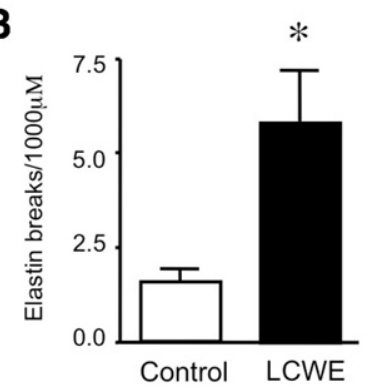

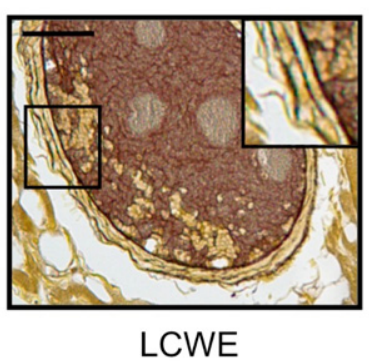

C

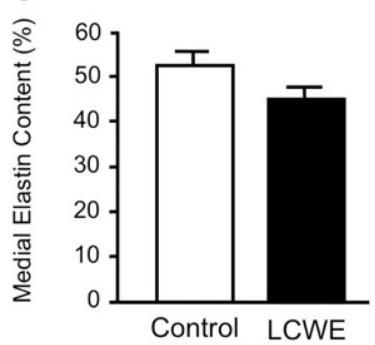

Figure 2. The LCWE induces fragmentation of coronary elastin. A: Representative sections of the coronary arteries after Hart's stain to stain the elastin brown, 42 days after PBS or LCWE. Insets demonstrate visible breaks in the external elastic lamina in LCWE-treated mice. Scale bars $=50 \mu \mathrm{m}$. B: Quantification of the number of visible breaks in the elastic lamina under $\times 40$ magnification per $1000 \mu \mathrm{m}$. Bars represent mean \pm SEM ( $n=5$ to 8 sections counted per group). ${ }^{*} P>0.05$ versus control. C: Quantification of the percentage of elastin-stained media versus the entire medial area using imaging software (Bioquant) in sections of the coronary arteries in PBS- and LCWE-injected mice at 42 days. Bars represent mean \pm SEM $(n=4$ to 6 per group) 


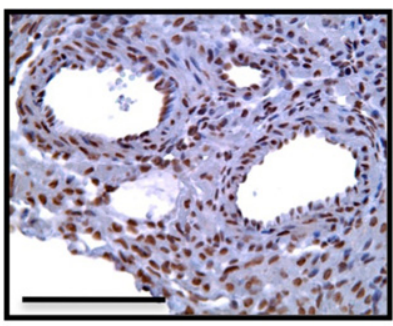

LCWE + $\lg G$

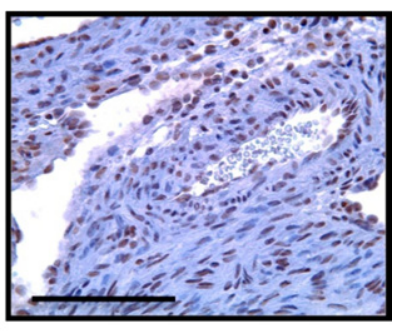

LCWE + TGF- $\beta$ nAb

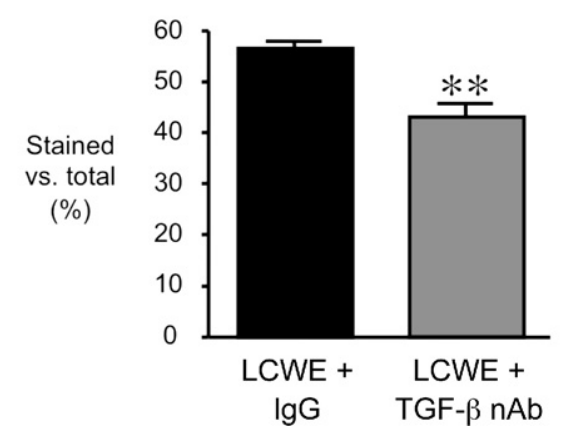

Figure 3. Administration of TGF- $\beta$ nAb suppresses the LCWE-mediated induction of TGF- $\beta$ in the coronary arteries. Representative sections of the coronary arteries are shown after immunostaining to detect pSmad2/3, 2 days after LCWE plus IgG or LCWE plus TGF- $\beta$ nAb. Total area of brown-stained nuclei versus total nuclei was quantified within the coronary wall. ${ }^{* *} P=$ 0.0013 versus LCWE plus IgG. Bars represent mean \pm SEM ( $n=6$ to 7 sections counted per group). Scale bars $=100 \mu \mathrm{m}$

found in the hearts of the LCWE-treated mice as early as 7 days, and persisted to 14 days, coinciding with the development of coronary arteritis (Figure 4B). Inhibition of TGF- $\beta$ did not further increase TNF- $\alpha$ mRNA levels but rather decreased levels slightly so that they were no longer significantly elevated at either 7 or 14 days after LCWE administration, although a strong trend persisted.

Then, we evaluated the effect of inhibiting TGF- $\beta$ on the degree of elastin degradation induced by LCWE at 42 days. Interestingly, blocking the basal TGF- $\beta$ activity in the controls resulted in marked dilation of the coronary vessels $(P<0.001)$ and thinning of the coronary arterial media in these developing mice (Figure 5, A and B). As observed in the previous experiments, treatment with IgG in addition to LCWE resulted in thinning, fraying, and fragmentation of the external elastic lamina. In accordance with our hypothesis, inhibition of TGF- $\beta$ accentuated the LCWE-mediated pathological characteristics in these animals, with areas of complete loss of the internal elastic lamina and marked disruption and dissolution of the external lamina. Interestingly, in contrast to the dilated coronary arteries of the mice treated with the TGF- $\beta$ nAb alone, the coronary arteries of the mice receiving LCWE in addition to TGF- $\beta$ appeared relatively constricted, despite the marked disruption of the elastic lamina evident in this group.

Quantification of elastin integrity and overall elastin content morphometrically demonstrated that although administration of the TGF- $\beta$ nAb alone resulted in thinning and dilation of the coronary wall, it did not result in fragmented elastin nor did it significantly decrease the level of medial elastin (Figure 5, C and D). Similarly, although
LCWE plus IgG induced fragmentation of the coronary elastin in the mice, the overall elastin content was not changed. However, blocking TGF- $\beta$ activity in combination with LCWE resulted in significantly greater fragmentation of the elastin compared with mice treated with LCWE plus IgG (Figure $5 \mathrm{C}$ ) and significantly reduced the medial elastin content (Figure 5D) $(P<0.001)$. Because TGF- $\beta$ can regulate elastin fiber assembly by stimulating the expression of tropoelastin, ${ }^{13,28}$ we determined whether blocking TGF- $\beta$ induced loss of the coronary elastin by suppressing tropoelastin protein expression. However, inhibition of TGF- $\beta$ did not affect tropoelastin protein levels in the LCWE-treated mice (data not shown).

Treatment of adult mice with LCWE with or without TGF- $\beta \mathrm{nAb}$ induced similar vascular pathological features to those observed in the neonates, except that TGF- $\beta$ nAb alone did not cause dilation of the arteries, suggesting that this effect was developmentally restricted. However, increased fragmentation of elastin was evident in the adult mice treated with LCWE plus TGF- $\beta$

A
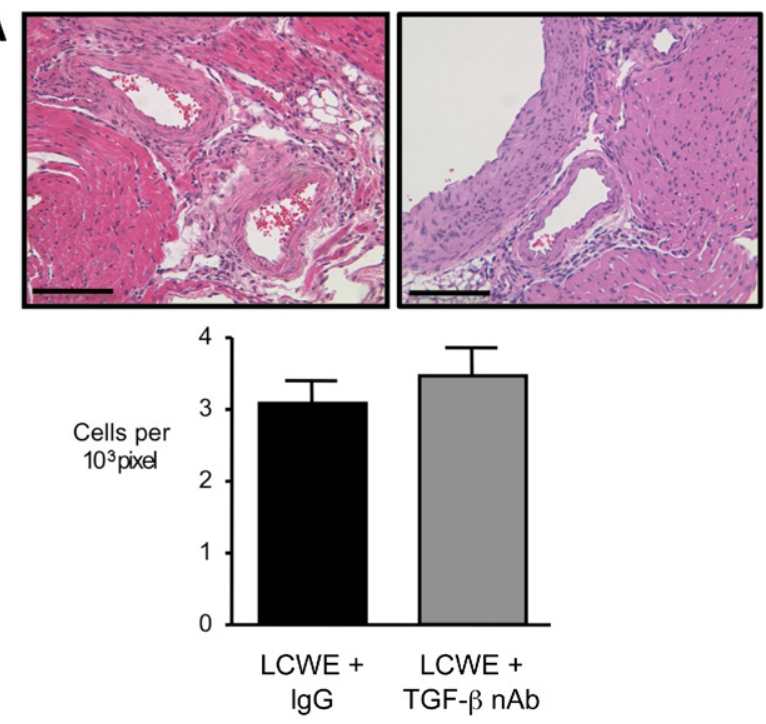

B
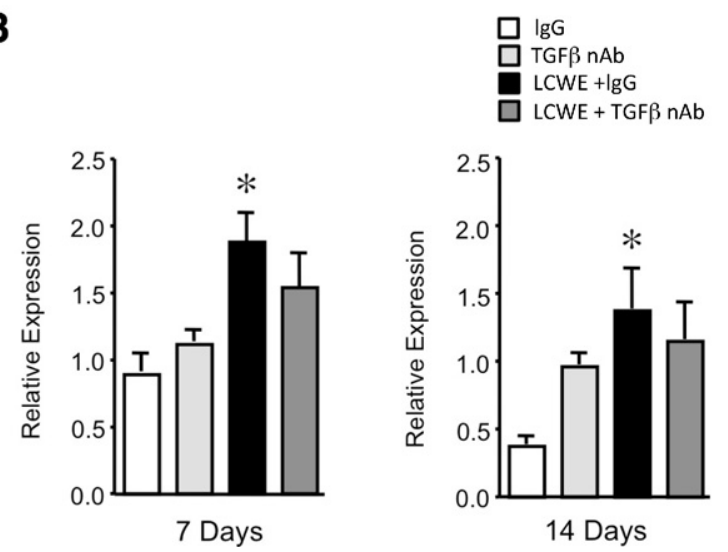

Figure 4. Inhibition of TGF- $\beta$ does not increase LCWE-mediated coronary arteritis. A: Representative H\&E sections of the coronary arteries 14 days after LCWE plus IgG or LCWE plus TGF- $\beta$ nAb demonstrate a similar degree of perivascular inflammatory cell infiltration. Scale bars $=100 \mu \mathrm{m}$. B: Quantitative PCR to detect the expression of TNF- $\alpha$ in the heart 7 and 14 days after LCWE. Bars represent mean $\pm \operatorname{SEM}(n=4$ to 6 per group). ${ }^{*} P<0.05$ versus IgG 
A
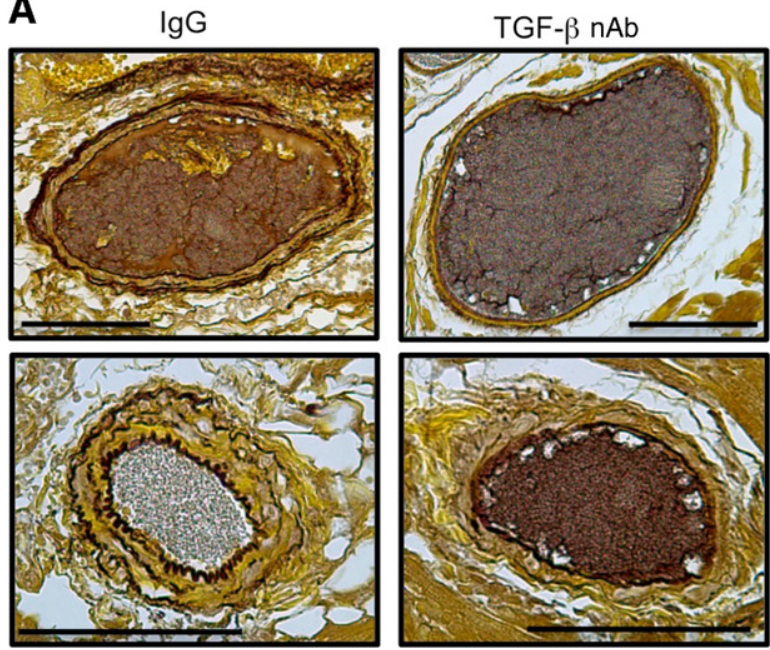

LCWE+ $\lg G$
LCWE+ TGF- $\beta$ nAb

B

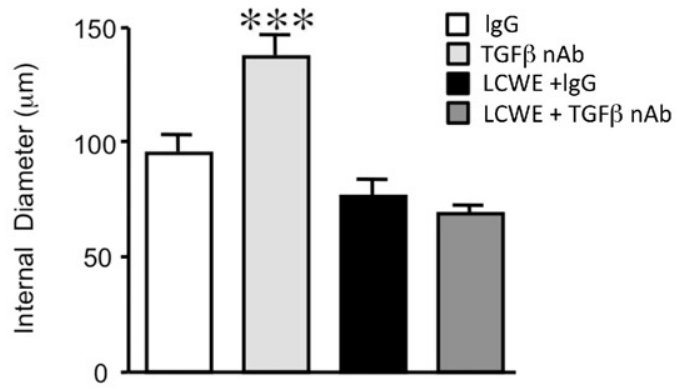

C

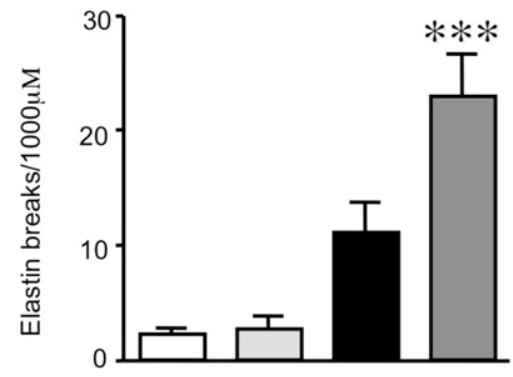

D

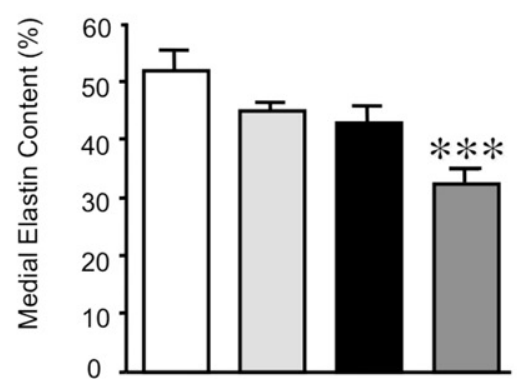

Figure 5. Inhibition of TGF- $\beta$ increases LCWE-mediated elastin degradation A: Representative sections of the coronary arteries after Hart's elastin staining 42 days after IgG, TGF- $\beta$ nAb, LCWE plus IgG, or LCWE plus TGF- $\beta$ nAb. B: Quantification of the internal diameter of the cross sections of the coronary arteries in each group. ${ }^{* * * * *} P<0.001$ versus IgG, LCWE plus IgG, and LCWE plus TGF- $\beta$ nAb. C: Quantification of the number of visible breaks in the elastic lamina under $\times 40$ magnification per $1000 \mu \mathrm{m}$. Bars represent mean $\pm \operatorname{SEM}\left(n=5\right.$ to 11 sections counted per group). ${ }^{* * *} P<0.001$ versus IgG. D: Quantification of the percentage of media staining for elastin versus the entire medial area using imaging software (Bioquant) in sections of the large coronary arteries in each group at 42 days. Bars represent mean \pm SEM ( $n=4$ to 6 per group). ${ }^{* * * *} P<0.001$ versus IgG. Scale bars $=100 \mu \mathrm{m}$.

$\mathrm{nAb}$. In addition, the trend toward reduced medial elastin observed with either LCWE or TGF- $\beta$ nAb in the neonates became significant in the adult; like the infants, the effect was greatest when the two agents were combined (see Supplemental Figure S1 at http://ajp.amjpathol.org).

To further explore the mechanism by which TGF- $\beta$ inhibition caused dilation of the developing coronary arteries, we evaluated the expression of matrix proteins that are essential to the strength and integrity of the vessel wall and regulate vascular tone and diameter. ${ }^{29}$ There were no significant changes in the gene expression of the various matrix components that we examined after either TGF- $\beta$ nAb or LCWE treatment at 7 days (see Supplemental Figure S2 at $h$ ttp://ajp.amjpathol.org). By 14 days, TGF- $\beta$ nAb resulted in a marked reduction in laminin- $\alpha 5$ $(P<0.05)$, an important regulator of vascular tone,${ }^{29}$ but did not alter levels of collagen $1-\alpha 1$ and collagen- $\alpha 2$ or laminin $\beta 2$ (Figure 6). Although LCWE plus IgG induced an increase in collagen $1-\alpha 1$ and collagen $1-\alpha 2$, only the increase in collagen 1- $\alpha 2$ was evident with LCWE plus TGF- $\beta$ nAb. There were no significant changes in collagen6- $\alpha 1$ or fibrillin- 1 in any of the four treatment groups nor did LCWE with or without TGF- $\beta$ nAb alter levels of laminin.

Then, we evaluated the deposition of extracellular matrix components in the coronary adventitia by Masson's trichrome staining, 42 days after LCWE, the point when TGF- $\beta$ nAb caused a significant loss of medial elastin. Treatment with the TGF- $\beta$ nAb in the control animals resulted in a significant reduction of adventitial matrix versus IgG-treated controls $(P<0.001)$ (Figure 7B). Despite the LCWE-mediated increase in collagen $1-\alpha 1$ and collagen 1- $\alpha 2$ mRNA expression at 14 days, extracellular matrix deposition was not significantly increased in the LCWE plus IgG-treated animals. In contrast, LCWE plus TGF- $\beta$ nAb increased matrix deposition in the coronary adventitia $(P<0.05)$, perhaps serving to prevent the vascular dilation despite the severe fragmentation and loss of the coronary elastin (Figure 7B).

\section{TGF- $\beta$ Blockade Increases MMP-9 Activity and Reduces PAl-1 Expression}

Blocking TGF- $\beta$ in combination with LCWE caused a significant loss of medial elastin without affecting tropoelastin levels, thereby suggesting that the mechanism was the result of enhanced degradation of insoluble elastin rather than impaired synthesis. Matrix metalloproteinases 2 and 9 have direct elastolytic activity, and their levels are increased in animal models of aneurysm and in patients with an abdominal aortic aneurysm. ${ }^{30,31}$ Furthermore, TNF- $\alpha$-mediated induction of MMP-9 activity is necessary for the elastin breakdown observed in the LCWE murine model of $\mathrm{KD} .{ }^{22}$ We evaluated the expression of MMP-9 by quantitative RT-PCR in the heart at 14 days and found no significant difference in MMP-9 expression in any of the four treatment groups (Figure 8A).

Transforming growth factor $\beta$ can inhibit proteolytic degradation of the extracellular matrix in two ways: i) by inducing the expression of TIMPs; and ii) by increasing 

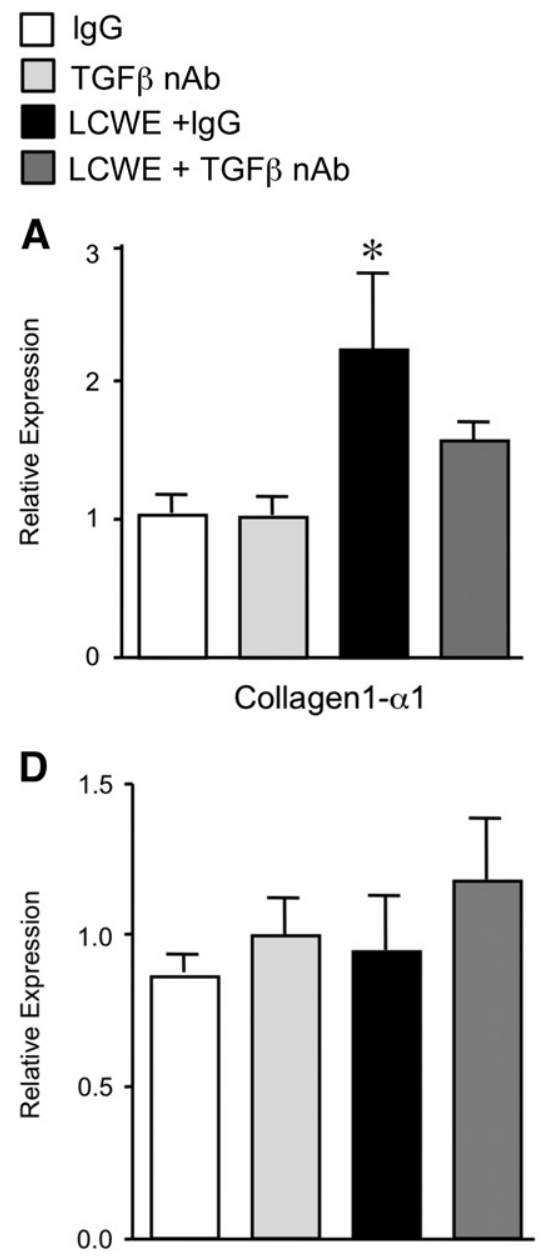

Fibrillin-1
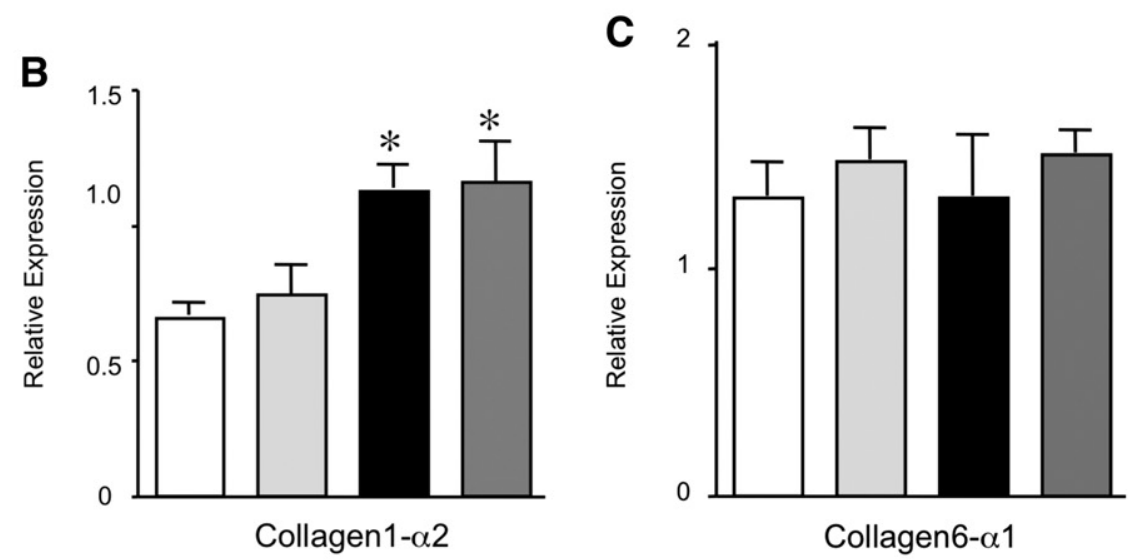

E

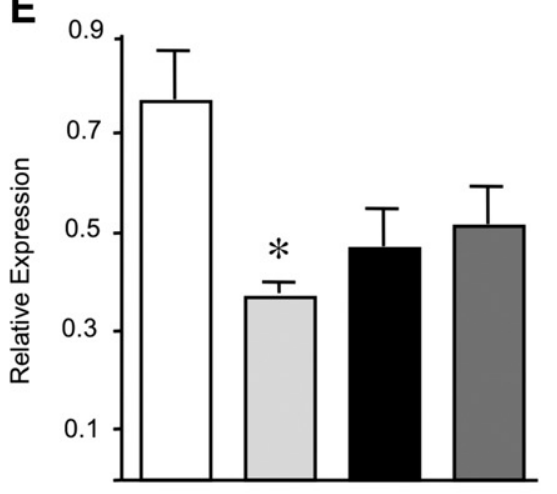

Laminin- $\alpha 5$

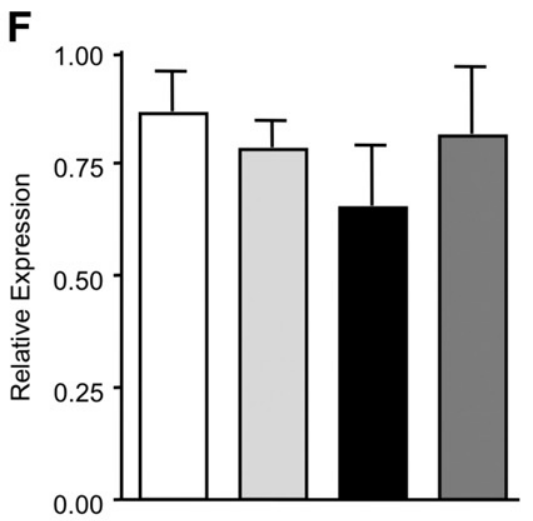

Laminin- $\beta 2$

Figure 6. The LCWE increases collagen-1 expression. Quantitative PCR to detect the expression of matrix components at 14 days: collagen $1-\alpha 1$ (A), collagen1- $\alpha 2$ $(\mathbf{B})$, collagen6- $\alpha 1(\mathbf{C})$, fibrillin-1 (D), laminin- $\alpha 5(\mathbf{E})$, and laminin- $\beta 2(\mathbf{F})$. Bars represent mean \pm SEM $\left(n=4\right.$ to 6 per group). ${ }^{*} P<0.05$ versus IgG.

inhibitors of plasmin, such as PAl-1, thereby decreasing plasmin-mediated MMP activation. ${ }^{14,15,32,33}$ Both are mechanisms that affect MMP activity, independent of mRNA levels. Therefore, to determine whether TGF- $\beta$ inhibition increased LCWE-mediated loss of elastin by augmenting either MMP-2 or MMP-9 activity, we performed gelatin zymography on heart homogenates 14 days after LCWE. We found no difference in either pro- or active MMP-2 in any of the groups (data not shown). Furthermore, neither TGF- $\beta$ nAb nor LCWE alone significantly increased active MMP-9 levels in the mice at 14 days. However, blocking TGF- $\beta$ in addition to LCWE resulted in a greater than threefold increase in MMP-9 activity $(P<$ 0.001) (Figure 8B).

The mechanism accounting for this increase in MMP-9 activity could not be attributed to changes in the protein expression of the MMP-9 inhibitors, TIMP-1 and TIMP-2, as determined by Western immunoblot (data not shown). However, TGF- $\beta$ blockade markedly reduced levels of PAI-1 in the LCWE-treated mice $(P<0.05)$ (Figure $8 \mathrm{C}$ ), suggesting that plasmin-mediated activation of MMP-9 likely contributes to the loss of medial elastin in this group.

\section{Discussion}

In this study, we demonstrate that TGF- $\beta$ signaling protects the coronary arteries against the destruction of elastin induced by coronary arteritis. This is in contrast to the pathological role of TGF- $\beta$ in the aortic aneurysms that form in MS, ${ }^{6}$ as assessed by the efficacy of TGF- $\beta$ blockade in both preventing aneurysms in the murine model of MS and slowing disease progression in patients with MS. ${ }^{7}$ In marked contrast to the MS model, our data suggest that with an inflammatory stimulus, loss of elastin is prevented by induction of TGF- $\beta$ and PAI-1-mediated repression of MMP-9 activation by plasmin. An unexpected observation is that TGF- $\beta$ signaling is essential during this postnatal window of coronary artery development because TGF- $\beta$ inhibition caused marked coronary wall thinning and dilation. We attribute this dilation to suppression of adventitial matrix deposition, including reduced expression of laminin- $\alpha 5$ (not to accentuated MMP-9 activity).

In this model of KD, LCWE caused an activation of TGF- $\beta$ beginning at 2 days and continuing through 14 days, concurrent with the induction of inflammatory cyto- 
A
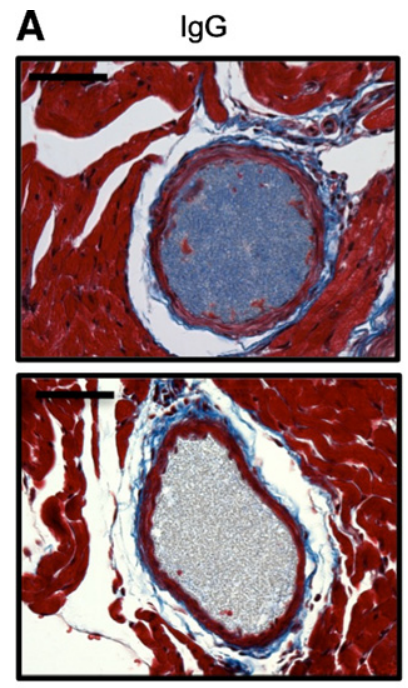

LCWE+ IgG
TGF- $\beta$ nAb
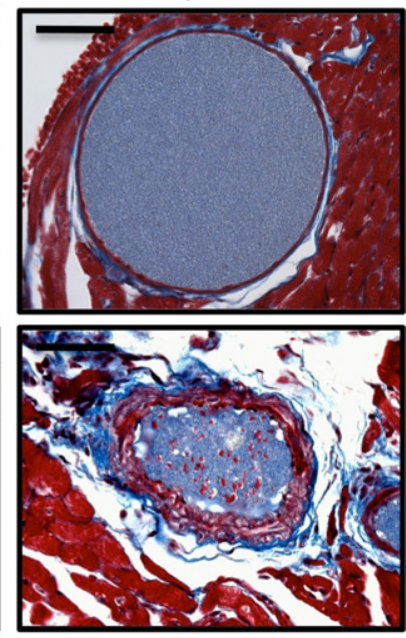

LCWE+ TGF- $\beta$ nAb
B

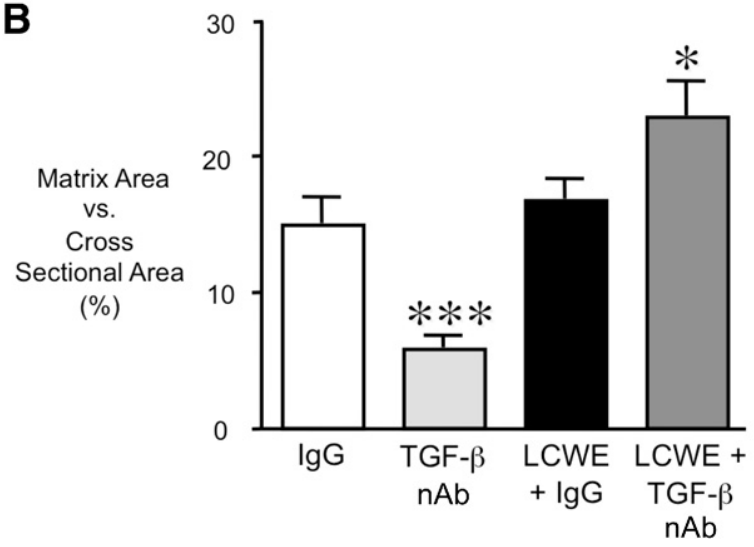

Figure 7. Increased matrix deposition in the coronary adventitia of LCWE plus TGF- $\beta$ nAb-treated mice. A: Representative sections of the coronary arteries taken at $\times 40$ magnification after Masson's trichrome staining 42 days after IgG, TGF- $\beta$ nAb, LCWE plus IgG, or LCWE plus TGF- $\beta$ nAb. B: Quantification of the percentage matrix versus total cross-sectional area of the coronary arteries for each group. Bars represent mean \pm SEM $(n=4$ to 6 per group). ${ }^{*} P<0.05$ and ${ }^{* * * *} P<0.001$ versus IgG. Scale bars $=50 \mu \mathrm{m}$.

kines and the development of coronary arteritis previously demonstrated. ${ }^{21}$ Tissue samples from the coronary arteries of patients with KD are limited and were obtained only from patients with fatal complications, making identification of the molecular mediators leading to CALs challenging. Evidence suggests that dysregulation of TGF- $\beta$ signaling occurs in patients with KD. Increased TGF- $\beta 1$ protein expression is found in the coronary smooth muscle cells in patients with KD. ${ }^{34,35}$ However, although one study ${ }^{36}$ found that serum levels of TGF- $\beta 1$ were increased in patients with acute KD compared with febrile controls, another study ${ }^{37}$ documented that levels were decreased. Therefore, the role that TGF- $\beta$ plays in the pathogenesis of inflammatory arteritis, such as KD, remains unclear.

We observed that the LCWE-mediated induction of TGF- $\beta$ was followed by the fragmentation of coronary elastin and that the inhibition of TGF- $\beta$ markedly increased the loss of elastin in association with accentuation of MMP-9 activity. Degradation of elastin is a key

feature of aneurysm development, and extensive clinical and experimental evidence demonstrates that an imbalance between the proteinases and their endogenous inhibitors influences the development and progression of arterial aneurysms. ${ }^{38}$ Matrix metalloproteinase 9 appears to be a key factor affecting this balance, with increased activity found in aneurysmal tissue taken from patients with an abdominal aortic aneurysm and $\mathrm{MS}^{39}$ in the coronary arteries of children with fatal $\mathrm{KD},{ }^{30}$ and in ani-
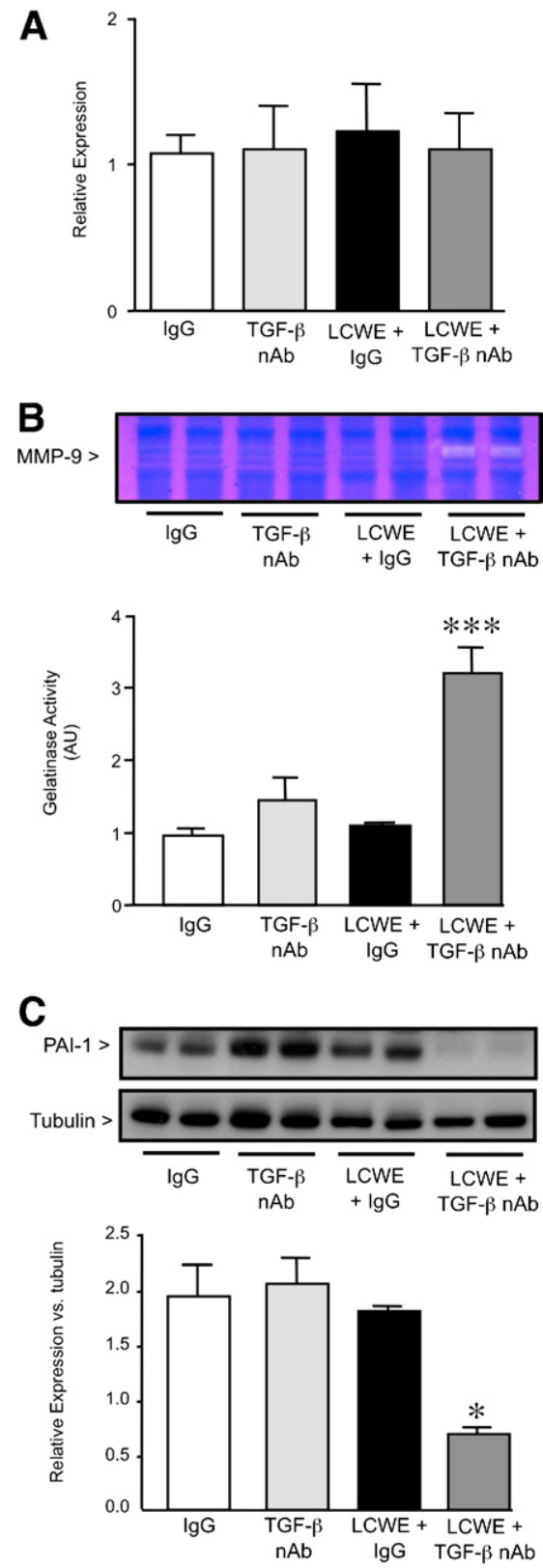

Figure 8. Inhibition of TGF- $\beta$ increases MMP-9 activity and reduces plasminogen activator inhibitor-1 in LCWE-treated mice. A: Quantitative PCR to detect MMP-9 expression in the heart at 14 days. B: Gelatin zymography was performed using total heart homogenates obtained 14 days after IgG, TGF- $\beta$ nAb, LCWE plus IgG, or LCWE plus TGF- $\beta$ nAb injection to detect active MMP-9. Bars represent mean $\pm \operatorname{SEM}\left(n=4\right.$ to 6 per group). ${ }^{* * * *} P<0.001$ versus IgG controls. AU indicates arbitrary unit. C: Western immunoblot analysis was performed to detect PAI-1 protein expression at 14 days after IgG, TGF- $\beta$ nAb, LCWE plus IgG, or LCWE plus TGF- $\beta$ nAb. Bars represent mean $\pm \operatorname{SEM}\left(n=4\right.$ to 6 per group). ${ }^{*} P<0.05$ versus IgG. 
mal models of abdominal aortic aneurysm. ${ }^{39-41}$ Heightened MMP-9 activity is also found in the coronary arteries of LCWE-treated animals, localizing to the vascular smooth muscle cells. ${ }^{22}$ Interestingly, we observed an increase in active MMP-9 in the animals treated with LCWE and TGF- $\beta$ nAb by 14 days, before the point when MMP-9 activity is increased in mice treated with LCWE alone. ${ }^{22}$ This suggests that TGF- $\beta$ blockade both enhances and accelerates the proteolytic process.

In addition to suppressing proteolysis, TGF- $\beta$ can modulate inflammation by repressing the transcription ${ }^{10}$ and mRNA stability ${ }^{42}$ of inflammatory cytokines. The critical role of TGF- $\beta$ in immune regulation is evident in the phenotype of TGF- $\beta 1$-null mice, demonstrating widespread tissue inflammation and persistent T-cell activation. ${ }^{43}$ Dysregulation of T-cell activation, resulting from a polymorphism within the inositol 1,4,5-triphosphate 3-kinase $\mathrm{C}$ gene, has recently been identified as a key factor determining KD susceptibility and risk for coronary artery aneurysms. ${ }^{44}$ Patients with the $C$ allele have reduced levels of inositol 1,4,5-triphosphate 3-kinase $\mathrm{C}$, a protein that suppresses T-cell activation by decreasing inositol triphosphate-mediated calcium influx and nuclear factor of activated T cells signaling. Transforming growth factor $\beta$ can decrease inositol triphosphate receptor expression and calcium influx in vascular smooth muscle. ${ }^{45}$ Therefore, although the TGF- $\beta$ blockade did not increase the number of infiltrating inflammatory cells or the expression of TNF- $\alpha$, future studies could be important to determine whether TGF- $\beta$ blockade in this model increases T-cell activation by derepressing inositol triphosphate receptor expression and enhancing nuclear factor of activated $T$ cells signaling.

Interestingly, in the absence of LCWE, TGF- $\beta$ blockade in the young mice caused dilation of the coronary arteries. Active TGF- $\beta$ signaling in the coronary arteries was found beginning at the age of 1 week and continuing through the age of 3 weeks. Taken together, these data suggest that local activation of TGF- $\beta$ during the early postnatal period is a requirement of normal coronary arterial development. Transforming growth factor $\beta$ regulates matrix components, such as collagen and laminin, ${ }^{46-49}$ that serve to limit blood vessel distention in response to pulsatile flow. Although we found no difference in collagen expression in this group, blocking TGF- $\beta$ signaling in the developing coronary artery was associated with a significant reduction of laminin- $\alpha 5$ and a decrease in adventitial matrix deposition. The laminins have a specific role in the regulation of blood vessel diameter because deletion of either laminin- $\alpha 4$ or laminin- $\alpha 5$ results in vessels with larger vascular lumens. ${ }^{46,50}$ Laminin- $\alpha 5$ expression in the vascular basement membrane begins in the mouse at E13.5 and increases postnatally, supporting its role in stabilizing the developing vasculature.

The administration of LCWE in combination with TGF- $\beta$ blockade reduced PAI-1, increased MMP-9 activity, and caused severe fragmentation of the internal elastic lamina and almost complete dissolution of the external elastic lamina; however, coronary dilation did not occur. The increase in matrix deposition demonstrated by trichrome staining likely limited dilation. However, collagen synthesis, as judged by mRNA expression, was not greater in the group treated with LCWE plus TGF- $\beta$ compared with those treated with LCWE plus IgG, suggesting that other matrix components (eg, fibronectin or osteopontin) predominated in this constrictive remodeling response, similar to that seen in the adventitial fibrosis that occurs after other types of vascular injury. ${ }^{51}$ Furthermore, although loss of elastin is an early feature of aneurysm formation, recent evidence suggests that other factors are likely required for the vessel dilation that occurs in aneurysm formation, including apoptosis of vascular smooth muscle cells ${ }^{52}$ and alterations in smooth muscle cell contractile proteins. ${ }^{53}$

It is also possible that a transient phase of coronary dilation preceded the constrictive remodeling observed in the LCWE-treated mice, similar to that seen in the clinical setting. Up to $10 \%$ of patients with a history of KD and CAL subsequently develop coronary stenosis, suggesting that persistent remodeling occurs even after the initial inflammation resolves. It is this later constrictive remodeling that accounts for most of the morbidity and mortality from $\mathrm{KD}$, with affected patients at risk for myocardial ischemia and sudden death and often requiring interventions such as balloon angioplasty, coronary bypass, or cardiac transplantation. ${ }^{54}$ Interestingly, even patients with $\mathrm{KD}$ without a history of CAL have evidence of increased stiffness of the coronary arteries compared with controls ${ }^{55,56}$; and increased stiffness is observed in association with reduced elastin. ${ }^{57}$ In addition, patients with KD have high levels of endothelin- 1 and impaired coronary artery vasodilation, suggesting that an imbalance in vasoconstrictive and vasodilatory factors contributes to the disease. ${ }^{58}$ The coronary circulation of the mice was not injected with vasodilators before injection of barium; therefore, it is possible that heightened vasoconstriction in the LCWE-treated animals was an additional factor limiting coronary distention in these groups.

In summary, we demonstrate that TGF- $\beta$ inhibition in a murine model of KD worsens disease severity, increasing elastin fragmentation and loss by suppressing PAI-1 and markedly increasing MMP-9 activity. We also identified a novel role for TGF- $\beta$ in the stabilization of the growing coronary arteries because inhibition during this developmental window caused marked thinning and dilation. This study has important implications, particularly in light of the recent identification of TGF- $\beta$ as a critical pathological mediator in the aneurysms forming in MS. First, it demonstrates that the molecular mechanisms leading to aneurysms in genetic and inflammatory diseases are distinct. Second, it suggests that therapeutic strategies to block TGF- $\beta$ are unlikely to be of benefit in KD and could be detrimental, particularly during early development.

\section{Acknowledgments}

We thank Robert P. Mecham, Ph.D., for providing the tropoelastin antibody. 


\section{References}

1. Falcini F: Kawasaki disease. Curr Opin Rheumatol 2006, 18:33-38

2. Newburger JW, Takahashi M, Gerber MA, Gewitz MH, Tani LY, Burns JC, Shulman ST, Bolger AF, Ferrieri P, Baltimore RS, Wilson WR, Baddour LM, Levison ME, Pallasch TJ, Falace DA. Taubert KA; Committee on Rheumatic Fever, Endocarditis, and Kawasaki Disease, Council on Cardiovascular Disease in the Young, American Heart Association: Diagnosis, treatment, and long-term management of Kawasaki disease: a statement for health professionals from the Committee on Rheumatic Fever, Endocarditis, and Kawasaki Disease, Council on Cardiovascular Disease in the Young, American Heart Association. Pediatrics 2004, 114:1708-1733

3. Sakalihasan N, Limet R, Defawe OD: Abdominal aortic aneurysm. Lancet 2005, 365:1577-1589

4. Shimizu K, Mitchell RN, Libby P: Inflammation and cellular immune responses in abdominal aortic aneurysms. Arterioscler Thromb Vasc Biol 2006, 26:987-994

5. Nakamura Y, Yanagawa H, Ojima T, Kawasaki T, Kato H: Cardiac sequelae of Kawasaki disease among recurrent cases. Arch Dis Child 1998, 78:163-165

6. Habashi JP, Judge DP, Holm TM, Cohn RD, Loeys BL, Cooper TK, Myers L, Klein EC, Liu G, Calvi C, Podowski M, Neptune ER, Halushka MK, Bedja D, Gabrielson K, Rifkin DB, Carta L, Ramirez F, Huso DL, Dietz HC: Losartan, an AT1 antagonist, prevents aortic aneurysm in a mouse model of Marfan syndrome. Science 2006, 312:117-121

7. Brooke BS, Habashi JP, Judge DP, Patel N, Loeys B, Dietz HC 3rd: Angiotensin II blockade and aortic-root dilation in Marfan's syndrome. N Engl J Med 2008, 358:2787-2795

8. Nichols L, Lagana S, Parwani A: Coronary artery aneurysm: a review and hypothesis regarding etiology. Arch Pathol Lab Med 2008, 132: 823-828

9. DiChiara MR, Kiely JM, Gimbrone MA Jr, Lee ME, Perrella MA, Topper $\mathrm{JN}$ : Inhibition of E-selectin gene expression by transforming growth factor beta in endothelial cells involves coactivator integration of Smad and nuclear factor kappaB-mediated signals. J Exp Med 2000, 192:695-704

10. Feinberg MW, Shimizu K, Lebedeva M, Haspel R, Takayama K, Chen Z, Frederick JP, Wang XF, Simon DI, Libby P, Mitchell RN, Jain MK: Essential role for Smad3 in regulating MCP-1 expression and vascular inflammation. Circ Res 2004, 94:601-608

11. Boak AM, Roy R, Berk J, Taylor L, Polgar P, Goldstein RH, Kagan HM: Regulation of lysyl oxidase expression in lung fibroblasts by transforming growth factor-beta 1 and prostaglandin E2. Am J Respir Cell Mol Biol 1994, 11:751-755

12. Kuang PP, Joyce-Brady M, Zhang XH, Jean JC, Goldstein RH: Fibulin-5 gene expression in human lung fibroblasts is regulated by TGF-beta and phosphatidylinositol 3-kinase activity. Am J Physiol Cell Physiol 2006, 291:C1412-C1421

13. McGowan SE, Jackson SK, Olson PJ, Parekh T, Gold LI: Exogenous and endogenous transforming growth factors-beta influence elastin gene expression in cultured lung fibroblasts. Am J Respir Cell Mol Biol 1997, 17:25-35

14. Akool el S, Doller A, Muller R, Gutwein P, Xin C, Huwiler A, Pfeilschifter $J$, Eberhardt W: Nitric oxide induces TIMP-1 expression by activating the transforming growth factor beta-Smad signaling pathway. J Biol Chem 2005, 280:39403-39416

15. Kutz SM, Higgins CE, Samarakoon R, Higgins SP, Allen RR, Qi L, Higgins PJ: TGF-beta 1-induced PAl-1 expression is E box/USFdependent and requires EGFR signaling. Exp Cell Res 2006, 312: 1093-1105

16. Dai J, Losy F, Guinault AM, Pages C, Anegon I, Desgranges P, Becquemin JP, Allaire E: Overexpression of transforming growth factor-beta1 stabilizes already-formed aortic aneurysms: a first approach to induction of functional healing by endovascular gene therapy. Circulation 2005, 112:1008-1015

17. Thompson RW, Curci JA, Ennis TL, Mao D, Pagano MB, Pham CT: Pathophysiology of abdominal aortic aneurysms: insights from the elastase-induced model in mice with different genetic backgrounds. Ann N Y Acad Sci 2006, 1085:59-73

18. Yoshimura K, Aoki H, Ikeda Y, Fujii K, Akiyama N, Furutani A, Hoshii Y, Tanaka N, Ricci R, Ishihara T, Esato K, Hamano K, Matsuzaki M:
Regression of abdominal aortic aneurysm by inhibition of c-Jun N-terminal kinase. Nat Med 2005, 11:1330-1338

19. Lemaitre V, Soloway PD, D'Armiento J: Increased medial degradation with pseudo-aneurysm formation in apolipoprotein E-knockout mice deficient in tissue inhibitor of metalloproteinases-1. Circulation 2003, 107:333-338

20. Hui-Yuen JS, Duong TT, Yeung RS: TNF-alpha is necessary for induction of coronary artery inflammation and aneurysm formation in an animal model of Kawasaki disease. J Immunol 2006, 176:6294-6301

21. Duong TT, Silverman ED, Bissessar MV, Yeung RS: Superantigenic activity is responsible for induction of coronary arteritis in mice: an animal model of Kawasaki disease. Int Immunol 2003, 15:79-89

22. Lau AC, Duong TT, Ito S, Yeung RS: Matrix metalloproteinase 9 activity leads to elastin breakdown in an animal model of Kawasaki disease. Arthritis Rheum 2008, 58:854-863

23. Bland RD, Ertsey R, Mokres LM, Xu L, Jacobson BE, Jiang S, Alvira CM, Rabinovitch M, Shinwell ES, Dixit A: Mechanical ventilation uncouples synthesis and assembly of elastin and increases apoptosis in lungs of newborn mice: prelude to defective alveolar septation during lung development? Am J Physiol Lung Cell Mol Physiol 2008, 294: L3-L14

24. Alvira CM, Abate A, Yang G, Dennery PA, Rabinovitch M: Nuclear factor-kappaB activation in neonatal mouse lung protects against lipopolysaccharide-induced inflammation. Am J Respir Crit Care Med 2007, 175:805-815

25. Jones PL, Crack J, Rabinovitch M: Regulation of tenascin-C, a vascular smooth muscle cell survival factor that interacts with the alpha $\checkmark$ beta 3 integrin to promote epidermal growth factor receptor phosphorylation and growth. J Cell Biol 1997, 139:279-293

26. Rosenkranz ME, Schulte DJ, Agle LM, Wong MH, Zhang W, Ivashkiv L, Doherty TM, Fishbein MC, Lehman TJ, Michelsen KS, Arditi M: TLR2 and MyD88 contribute to Lactobacillus casei extract-induced focal coronary arteritis in a mouse model of Kawasaki disease. Circulation 2005, 112:2966-2973

27. Schulte DJ, Yilmaz A, Shimada K, Fishbein MC, Lowe EL, Chen S, Wong M, Doherty TM, Lehman T, Crother TR, Sorrentino R, Arditi M: Involvement of innate and adaptive immunity in a murine model of coronary arteritis mimicking Kawasaki disease. J Immunol 2009, 183 $5311-5318$

28. Kucich U, Rosenbloom JC, Abrams WR, Rosenbloom J: Transforming growth factor-beta stabilizes elastin mRNA by a pathway requiring active Smads, protein kinase C-delta, and p38. Am J Respir Cell Mol Biol 2002, 26:183-188

29. Jakobsson L, Domogatskaya A, Tryggvason K, Edgar D, ClaessonWelsh L: Laminin deposition is dispensable for vasculogenesis but regulates blood vessel diameter independent of flow. FASEB J 2008, 22:1530-1539

30. Gavin PJ, Crawford SE, Shulman ST, Garcia FL, Rowley AH: Systemic arterial expression of matrix metalloproteinases 2 and 9 in acute Kawasaki disease. Arterioscler Thromb Vasc Biol 2003, 23:576-581

31. Longo GM, Xiong W, Greiner TC, Zhao Y, Fiotti N, Baxter BT: Matrix metalloproteinases 2 and 9 work in concert to produce aortic aneurysms. J Clin Invest 2002, 110:625-632

32. Yamanaka M, Shegogue D, Pei H, Bu S, Bielawska A, Bielawski J, Pettus B, Hannun YA, Obeid L, Trojanowska M: Sphingosine kinase 1 (SPHK1) is induced by transforming growth factor-beta and mediates TIMP-1 up-regulation. J Biol Chem 2004, 279:53994-54001

33. Allaire E, Hasenstab D, Kenagy RD, Starcher B, Clowes MM, Clowes AW: Prevention of aneurysm development and rupture by local overexpression of plasminogen activator inhibitor-1. Circulation 1998, 98:249-255

34. Suzuki A, Miyagawa-Tomita S, Komatsu K, Nakazawa M, Fukaya T, Baba K, Yutani C: Immunohistochemical study of apparently intact coronary artery in a child after Kawasaki disease. Pediatr Int 2004, 46:590-596

35. Suzuki A, Miyagawa-Tomita S, Komatsu K, Nishikawa T, Sakomura Y Horie T, Nakazawa M: Active remodeling of the coronary arterial lesions in the late phase of Kawasaki disease: immunohistochemical study. Circulation 2000, 101:2935-2941

36. Terai M, Yasukawa K, Narumoto S, Tateno S, Oana S, Kohno Y: Vascular endothelial growth factor in acute Kawasaki disease. Am J Cardiol 1999, 83:337-339

37. Matsubara T, Umezawa Y, Tsuru S, Motohashi T, Yabuta K, Furukawa $\mathrm{S}$ : Decrease in the concentrations of transforming growth factor-beta 
1 in the sera of patients with Kawasaki disease. Scand J Rheumatol 1997, 26:314-317

38. Jones JA, Beck C, Barbour JR, Zavadzkas JA, Mukherjee R, Spinale FG, Ikonomidis JS: Alterations in aortic cellular constituents during thoracic aortic aneurysm development: myofibroblast-mediated vascular remodeling. Am J Pathol 2009, 175:1746-1756

39. Chung AW, Au Yeung K, Sandor GG, Judge DP, Dietz HC, van Breemen C: Loss of elastic fiber integrity and reduction of vascular smooth muscle contraction resulting from the upregulated activities of matrix metalloproteinase-2 and -9 in the thoracic aortic aneurysm in Marfan syndrome. Circ Res 2007, 101:512-522

40. Ikonomidis JS, Gibson WC, Butler JE, McClister DM, Sweterlitsch SE, Thompson RP, Mukherjee R, Spinale FG: Effects of deletion of the tissue inhibitor of matrix metalloproteinases- 1 gene on the progression of murine thoracic aortic aneurysms. Circulation 2004, 110: II268-II273

41. Kaito K, Urayama H, Watanabe G: Doxycycline treatment in a mode of early abdominal aortic aneurysm. Surg Today 2003, 33:426-433

42. Dai $Y$, Datta S, Novotny M, Hamilton TA: TGFbeta inhibits LPSinduced chemokine mRNA stabilization. Blood 2003, 102:1178-1185

43. Kulkarni AB, Huh CG, Becker D, Geiser A, Lyght M, Flanders KC, Roberts AB, Sporn MB, Ward JM, Karlsson S: Transforming growth factor beta 1 null mutation in mice causes excessive inflammatory response and early death. Proc Natl Acad Sci U S A 1993, 90:770774

44. Onouchi Y, Gunji T, Burns JC, Shimizu C, Newburger JW, Yashiro M, Nakamura $Y$, Yanagawa $H$, Wakui $K$, Fukushima $Y$, Kishi $F$, Hamamoto K, Terai M, Sato Y, Ouchi K, Saji T, Nariai A, Kaburagi Y Yoshikawa T, Suzuki K, Tanaka T, Nagai T, Cho H, Fujino A, Sekine A, Nakamichi R, Tsunoda T, Kawasaki T, Nakamura Y, Hata A: ITPKC functional polymorphism associated with Kawasaki disease susceptibility and formation of coronary artery aneurysms. Nat Genet 2008, 40:35-42

45. Sharma K, McGowan TA, Wang L, Madesh M, Kaspar V, Szalai G, Thomas AP, Hajnoczky G: Inhibition of type I and III IP(3)Rs by TGF-beta is associated with impaired calcium release in mesangial cells. Am J Physiol Renal Physiol 2000, 278:F1022-F1029

46. Thyboll J, Kortesmaa J, Cao R, Soininen R, Wang L, livanainen A, Sorokin L, Risling M, Cao Y, Tryggvason K: Deletion of the laminin alpha4 chain leads to impaired microvessel maturation. Mol Cell Biol 2002, 22:1194-1202

47. Poschl E, Schlotzer-Schrehardt U, Brachvogel B, Saito K, Ninomiya Y, Mayer U: Collagen IV is essential for basement membrane stability but dispensable for initiation of its assembly during early development. Development 2004, 131:1619-1628
48. Liu X, Wu H, Byrne M, Krane S, Jaenisch R: Type III collagen is crucial for collagen I fibrillogenesis and for normal cardiovascular development. Proc Natl Acad Sci U S A 1997, 94:1852-1856

49. Rahkonen O, Su M, Hakovirta H, Koskivirta I, Hormuzdi SG, Vuorio E, Bornstein P, Penttinen R: Mice with a deletion in the first intron of the Col1a1 gene develop age-dependent aortic dissection and rupture. Circ Res 2004, 94:83-90

50. Miner JH, Cunningham J, Sanes JR: Roles for laminin in embryogenesis: exencephaly, syndactyly, and placentopathy in mice lacking the laminin alpha5 chain. J Cell Biol 1998, 143:1713-1723

51. Michel JB, Thaunat O, Houard X, Meilhac O, Caligiuri G, Nicoletti A: Topological determinants and consequences of adventitial responses to arterial wall injury. Arterioscler Thromb Vasc Biol 2007, 27:1259-1268

52. Henderson EL, Geng YJ, Sukhova GK, Whittemore AD, Knox J, Libby $P$ : Death of smooth muscle cells and expression of mediators of apoptosis by $\mathrm{T}$ lymphocytes in human abdominal aortic aneurysms. Circulation 1999, 99:96-104

53. Guo DC, Pannu H, Tran-Fadulu V, Papke CL, Yu RK, Avidan N Bourgeois S, Estrera AL, Safi HJ, Sparks E, Amor D, Ades L, McConnell V, Willoughby CE, Abuelo D, Willing M, Lewis RA, Kim DH, Scherer S, Tung PP, Ahn C, Buja LM, Raman CS, Shete SS, Milewicz DM: Mutations in smooth muscle alpha-actin (ACTA2) lead to thoracic aortic aneurysms and dissections. Nat Genet 2007, 39:1488-1493

54. Kato H, Sugimura T, Akagi T, Sato N, Hashino K, Maeno Y, Kazue T, Eto G, Yamakawa R: Long-term consequences of Kawasaki disease: a 10- to 21-year follow-up study of 594 patients. Circulation 1996, 94:1379-1385

55. Cheung YF, O K, Woo CW, Armstrong S, Siow YL, Chow PC, Cheung EW: Oxidative stress in children late after Kawasaki disease: relationship with carotid atherosclerosis and stiffness. BMC Pediatr 2008, 8:20

56. Cheung YF, Wong SJ, Ho MH: Relationship between carotid intimamedia thickness and arterial stiffness in children after Kawasaki disease. Arch Dis Child 2007, 92:43-47

57. Shifren A, Durmowicz AG, Knutsen RH, Faury G, Mecham RP: Elastin insufficiency predisposes to elevated pulmonary circulatory pressures through changes in elastic artery structure. J Appl Physiol 2008, 105:1610-1619

58. Morise T, Takeuchi Y, Takeda R, Karayalcin U, Yachie A, Miyawaki T: Increased plasma endothelin levels in Kawasaki disease: a possible marker for Kawasaki disease. Angiology 1993, 44:719-723 